\title{
A Possible Mechanism behind the Discovery of Prussian Blue
}

\author{
Youxin Duan ${ }^{\dagger}$ and Junyan Zhang ${ }^{\dagger}, *$ \\ $\dagger$ State Key Laboratory of Solid Lubrication, Lanzhou Institute of Chemical Physics, Chinese Academy of Sciences, Lanzhou \\ 730000, China
}

\begin{abstract}
In this work, we synthesized Prussian Blue (PB) by pyrolysis of nitrogen-rich organic compounds and ferric/ferrous salts in the presence of alkali metal salt in inert atmosphere at high temperature, which was completely different from popular method based on the reaction of ferric ions and ferrocyanide ions. By exploring the history of Prussian Blue and some research results, we proposed a possible mechanism to explain the formation of Prussian Blue. The results may provide a new insight into the chemistry of $\mathrm{PB}$. By combining the properties of $\mathrm{PB}$ and carbon materials, the method may produce some interesting $\mathrm{PB} / \mathrm{C}$ composites which may be useful in different applications such as electrochemistry.
\end{abstract}

Recent years, iron and nitrogen-codoped carbon (Fe-N-C) materials have attracted tremendous attention in oxygen reduction reduction (ORR) electrocatalyst ${ }^{1,2}$ and other catalysis process ${ }^{3}$. The Fe-N-C materials are generally prepared by pyrolysis of mixture of iron, nitrogen and carbon precursors in in ert atmosphere. Nitrogen-rich organic compounds and biomass are usually used as both carbon and nitrogen precursors. The carbon and nitrogen could also be introduced respectively by different substances. For example, nitrogen-rich compounds such as urea ${ }^{4,5}$, dicyandiamide $^{6}$ and melamine ${ }^{6,7}$ always serve as nitrogen precursors. The iron precursors are always ferric/ferrous salts. The chemical composition and structure of the resulted materials are always complicated. For example, the iron species in these materials could be oxides $^{3,8}\left(\mathrm{Fe}_{2} \mathrm{O}_{3}, \mathrm{Fe}_{3} \mathrm{O}_{4}\right)$, carbide ${ }^{9,10}\left(\mathrm{Fe}_{3} \mathrm{C}\right)$ or in coordination structures $\left(\mathrm{Fe}-\mathrm{N}_{\mathrm{x}}, \mathrm{x}=2 \text { or } 4\right)^{11,12}$. The nitrogen speices are always doped in the carbon matrix in different forms such as pyridinic, pyrrolic, graphitic nitrogen or nitrogen oxides $\left(\mathrm{N}-\mathrm{O}_{\mathrm{x}}\right){ }^{13,14}$

Prussian Blue was the first synthetic pigment in history and had profound influence in the history of painting art. It also had unique properties in various scientific fields such as electrochemistry and magnetism. It is generally synthesized by the reaction of ferric ions and ferrocyanide ions. Recently, Prussian Blue was used as precursor to prepare $\mathrm{Fe}-\mathrm{N}-\mathrm{C}$ electrocatalyst by pyroly sis method. ${ }^{15,16}$

In present work, however, we have demonstrated that Prussian Blue (PB) could be obtained by the pyrolysis of the mixture of carbon, nitrogen and iron precursors when another key compound-alkali metal salt-was introduced into the system. The preparation procedure is as follows. Firstly, certain amounts of sucrose, urea, ferric sulfate $\left(\mathrm{Fe}_{2}\left(\mathrm{SO}_{4}\right)_{3}\right)$ and potassium sulfate $\left(\mathrm{K}_{2} \mathrm{SO}_{4}\right)$ was dissolved in water to form a homogeneous solution. The solution was then heated to evaporate the water and a black solid was resulted. The black solid was pyrolyzed at high temperature $\left(800^{\circ} \mathrm{C}\right)$ in Argon atmosphere to obtain a black material. The resulted material was washed by hydrochloric acid, deionized water and absolute ethanol respectively, and then dried to get black powder. Detailed experimental method could be found in supporting information. The whole process could be illustrated by Figure 1. The resulted PB dispersing in ethanol was showed in the right of Figure 1. The X-ray diffraction (XRD) pattern of the powder showed several strong and narrow peaks which were identical with the XRD pattern of $\mathrm{Fe}^{\mathrm{III}}{ }_{4}\left[\mathrm{Fe}^{\mathrm{II}}(\mathrm{CN})_{6}\right]_{3}$ (PDF \# 52-1907) (Figure 2). It can be seen that PB was really synthesized by the method above. For comparison, glycine was used as both carbon and nitrogen precursor and a uniform mixture of glycine, ferric sulfate, ferrous sulfate and potassium sulfate was also pyrolysed in Argon atmosphere. After washing by sulfuric acid solution, water and absolute ethanol and drying, the XRD pattern of the resulted materials also showed characteristic peaks of Prussian Blue (Figure 3).

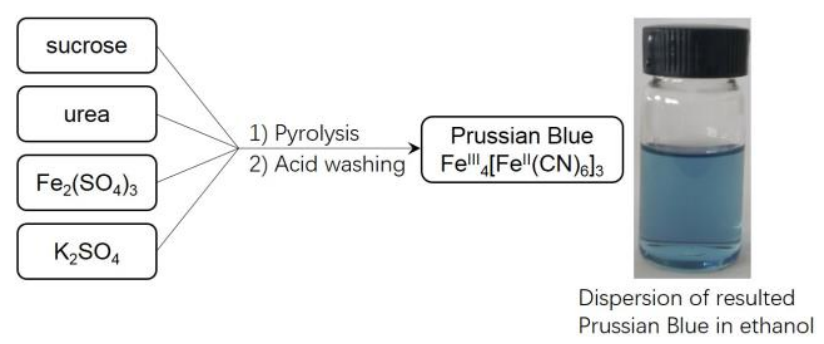

Figure 1. Synthesis of Prussian Blue by py roly sis of sucrose, urea, $\mathrm{Fe}_{2}\left(\mathrm{SO}_{4}\right)_{3}$ and $\mathrm{K}_{2} \mathrm{SO}_{4}$.

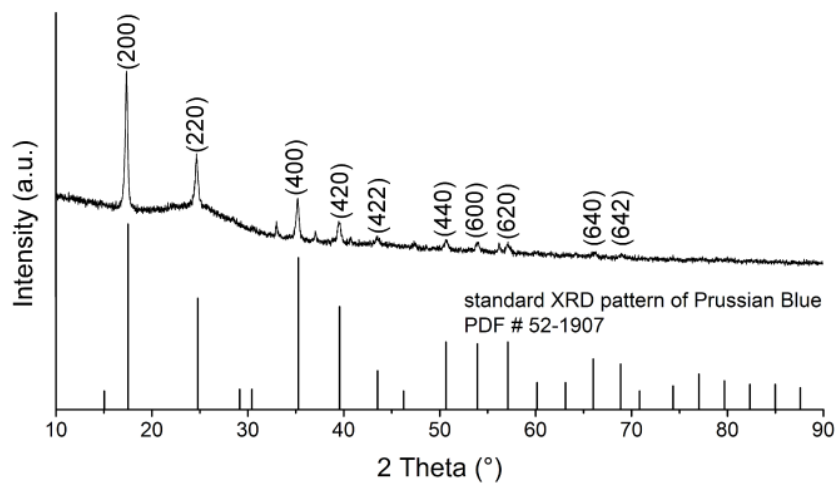

Figure 2. The XRD pattern of sample prepared by pyrolysis of sucrose, urea, ferric sulfate and potassium sulfate and the standard XRD pattern of Prussian Blue. 


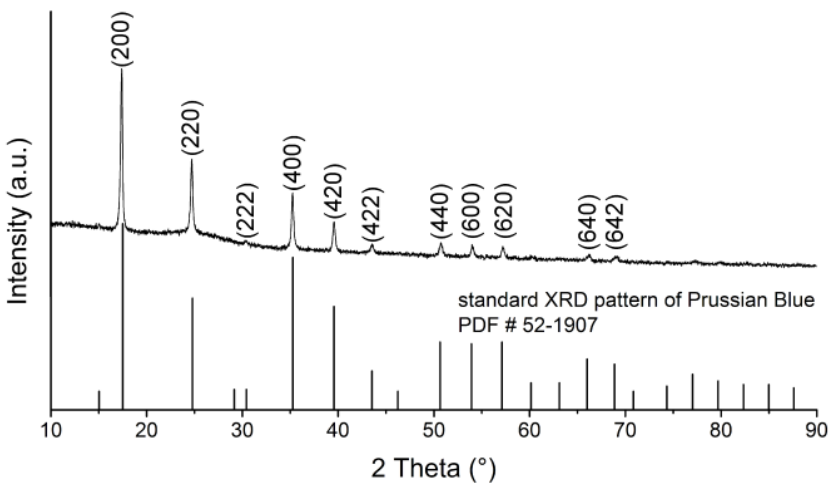

Figure 3. The XRD pattern of sample prepared by pyrolysis of glycine, ferric sulfate, ferrous sulfate and potassium sulfate and the standard XRD pattern of Prussian Blue.

The result was really unexpected. So what is the reason for the production of Prussian Blue? We could find some clues from the history of Prussian Blue.

Prussian Blue (PB), which has a chemical formula of $\mathrm{Fe}^{\mathrm{III}}{ }_{4}\left[\mathrm{Fe}^{\mathrm{II}}(\mathrm{CN})_{6}\right]_{3}$ or $\mathrm{KFe}^{\mathrm{III}}\left[\mathrm{Fe}^{\mathrm{II}}(\mathrm{CN})_{6}\right]$, was the first synthetic pigment in history and had profound influence in the history of painting art. It was discovered accidentally by a German colormaker named Diesbach in 18th century $(1704)^{17,18}$. He was used to produce a red pigment by extracting cochineal with alum $\left[\mathrm{KAl}\left(\mathrm{SO}_{4}\right)_{2} \bullet 12 \mathrm{H}_{2} \mathrm{O}\right]$, adding ferrous sulfate $\left(\mathrm{FeSO}_{4}\right)$ and precipitating the red color by adding potash $\left(\mathrm{K}_{2} \mathrm{CO}_{3}\right) .{ }^{17}$ On one occasion, he was short of potash and borrowed some from Dippel who used the potash in production of "animal oil". As a result, when Diesbach added the potash from Dippel into his solution as usual and concentrated the precipitation, he got a dark blue substance which was well-known as Prussian Blue from that time. It is wellknown nowadays that the PB could be synthesized by mixing solution of $\mathrm{Fe}^{3+}$ and potassium ferrocy anide $\left[\mathrm{K} 4 \mathrm{Fe}(\mathrm{CN})_{6}\right]$. However, in the story of discovering PB, what's the mechanism of forming PB? It is believed that the potash from Dippel was the key factor. According to Alexander $\mathrm{Kraft}^{18}$, the potash that Diesbach borrowed from Dippel had been contaminated by ferrocyanide, so that PB could be produced when the contaminated potash was added into the solution containing $\mathrm{Fe}^{2+}$ which could be easily oxidized into $\mathrm{Fe}^{3+}$ in air. So the key step was the formation of ferrocyanide or more specifically, the formation of cyanide. Why did the potash from Dippel contain ferrocy anide?

In 1724 , after 20 years of the discovery of PB, Woodward published a paper describing a general and effective method to prepare PB. ${ }^{17,19,20}$ The method firstly calcined alkali salts with bullock's blood and then added alum and ferrous sulfate into the solution of the resulted material to get greenish precipitate. After boiling the precipitate in hydrochloric solution, blue color was produced. At the same time, it was found that flesh or other substances from animals were as effective as bullock's blood in preparing PB. ${ }^{17}$ Because $\mathrm{Fe}^{2+}$ and $\mathrm{Fe}^{3+}$ (produced by oxidation of $\mathrm{Fe}^{2+}$ in air) could be supplied by ferrous sulfate, so the calcination of alkali salts with blood or animal substances was the source of cyanide. It is easy to conclude that the cy anide was from nitrogen and carbon elements in these organic substances. The mechanism of cyanide formation in the calcination of alkali salts and nitrogen-containing organic compounds could be explained by a research of VähäSavo et al. ${ }^{21}$ They found that alkali salts such as $\mathrm{K}_{2} \mathrm{CO}_{3}, \mathrm{Na}_{2} \mathrm{CO}_{3}$ and $\mathrm{K}_{2} \mathrm{SO}_{4}$ could transform nitrogen species in black liquor into cy anate in both pyrolysis and gasification processes. The study of Dayton et $\mathrm{al}^{22}$ also confirmed that in the combustion of biomass which had high content of alkali metal elements and nitrogen element and low content of chlorine, potassium cyanate was re- leased as the main form of alkali metal elements. So it is possible that in the calcination of alkali salts and $\mathrm{N}$-containing organic compounds, cyanate was firstly formed and served as an intermediate for the final formation of cyanide. Then the question is how cyanate was transformed to cyanide. According to a video on www.y outube. $\operatorname{com}^{23}$, the author firstly calcined a mixture of urea and potassium hydroxide to synthesize potassium cyanate and then calcined the resulted potassium cyanate with carbon. After washing the resulted mixture by hot water, filtrating to get a clear solution and mixing the resulted solution with a solution containing $\mathrm{Fe}^{2+}$ and $\mathrm{Fe}^{3+}$, it was surprising that a dark blue precipitation of Prussian Blue appeared. We can see that the reduction ability of carbon is so strong that it can capture the oxy gen atom of cyanate and reduce the cy anate to cy anide at high temperature. Based on this fact, we can deduce that when nitrogen-containing organic compounds was calcined with alkali salts, not only cyanate was formed, but also the cyanate was reduced to cyanide by carbon which was formed by the carbonization of organic compounds at high temperature in the calcination process. If iron(II) and iron(III) species existed in the system, Prussian Blue could be easily obtained.

According to above analysis, we can propose a possible mechanism to explain the formation of Prussian Blue. Firstly, carbon, nitrogen and oxygen element in the mixture were transformed to cyanate by the catalysis of alkali metal species. With the increasing of temperature, organic compounds decomposed to release reducing gases such as $\mathrm{H}_{2}$ and $\mathrm{CO}$ and eventually formed carbon materials. The reducing gases reduced partial $\mathrm{Fe}^{3+}$ to $\mathrm{Fe}^{2+}$ and the carbon reduced the cyanate to cyanide. So Prussian Blue was formed by cyanide, $\mathrm{Fe}^{3+}$ and $\mathrm{Fe}^{2+}$. The whole process could be illustrated by following process and Figure 4 .

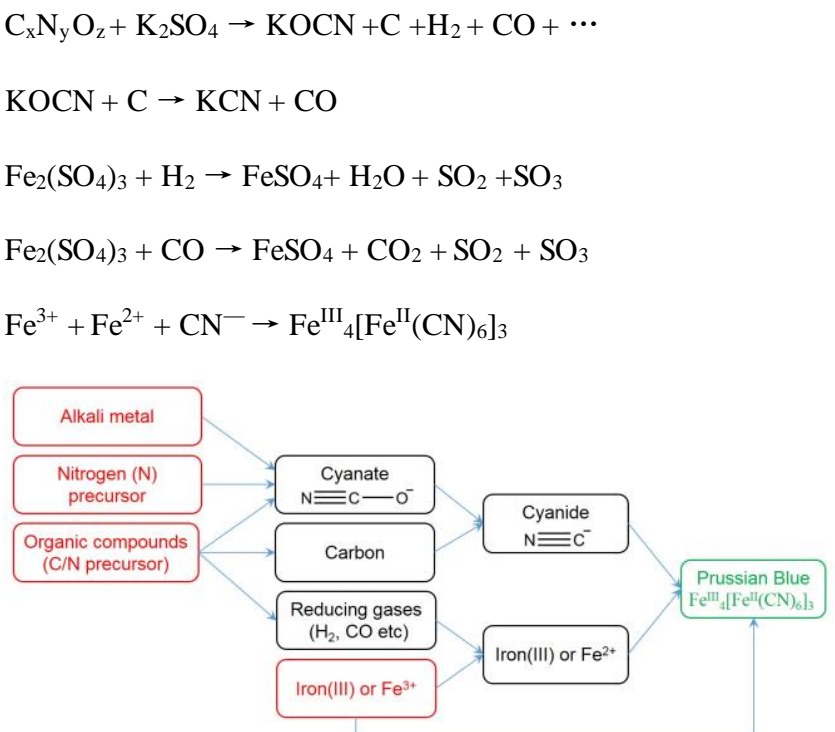

Figure 4. A possible mechanism of Prussian Blue formation in pyroly sis process.

We can see that in our experiment, the roles of each compounds are as follows:

(1) Sucrose or gly cine: decomposing at high temperature to form carbon and reducing gases such as $\mathrm{H}_{2}$ and $\mathrm{CO}$. Glycine can sverve as both carbon and nitrogen precursor.

(2) Urea: nitrogen precursor. Nitrogen-rich organic substances such as glycine, other amino acid or biomass can also serve as nitrogen precursor. In the discovery of Prussian Blue by Diesbach, it is very possible that the amino acids in the "animal oil" serve as carbon and nitrogen precursors. However, urea is special because 
it is the isomer of ammonium cyanate $\left(\mathrm{NH}_{4} \mathrm{OCN}\right)$ and it can react with alkali salts such as $\mathrm{Na}_{2} \mathrm{CO}_{3}$ or $\mathrm{K}_{2} \mathrm{SO}_{4}$ to form sodium cy anate $(\mathrm{NaOCN})$ or potassium cy anate $(\mathrm{KOCN})$.

(3) $\mathrm{K}_{2} \mathrm{SO}_{4}: \mathrm{K}^{+}$can transform the carbon, nitrogen and oxygen elements in precursors to cyanate and form potassium cyanate $(\mathrm{KOCN})$. The resulting potassium cyanate $(\mathrm{KOCN})$ could be reduced to potassium cy anide (KCN).

(4) $\mathrm{Fe}_{2}\left(\mathrm{SO}_{4}\right)_{3}$ : iron precursor. Partial Fe(III) could be reduced by reducing gases such as $\mathrm{H}_{2}$ and $\mathrm{CO}$ to $\mathrm{Fe}(\mathrm{II})$. $\mathrm{Fe}$ (II) could also be supplied by other salts such as $\mathrm{FeSO}_{4}$ or $\mathrm{FeCl}_{2}$. The $\mathrm{Fe}(\mathrm{III}), \mathrm{Fe}(\mathrm{II})$ and cyanide could combine to form Prussian Blue $\left(\mathrm{Fe}^{\mathrm{III}}{ }_{4}\left[\mathrm{Fe}^{\mathrm{II}}(\mathrm{CN})_{6}\right]_{3}\right)$.

Nowadays, Prussian Blue could be prepared by potassium ferrocy anide and ferric salt conven iently and it seems that its original preparation method has been forgotten. However, with the rapid development of nanotechnology and materials science, it is possible to take advantage of the method above to achieve some interesting and useful goals and functions. Our method could synthesize not only PB but also PB/C composites. Due to the diversity of carbon materials such as graphene, nanotube and amorphous carbon, it is convenient to prepare various types of $\mathrm{PB} / \mathrm{C}$ composites for different applications such as electrochemistry by taking advantage of the properties of PB and carbon materials. For example, it has been showed that the reduced form of Prussian Blue had cataly tic activity for reduction of oxygen and hydrogen peroxide in acid aqueous electrolyte. ${ }^{24}$ The applications of PB in other fields such as electrode materials for batteries ${ }^{25,26}$ and electrochemical sensors ${ }^{27}$ have also been studied. By combining the unique and excellent electrochemical properties of $\mathrm{PB}$ and carbon materials, the resulted materials may have great potential in these fields. In addition, by adding other transition metal elements such as nickel, cobalt and copper, the method may be applied to prepare Prussian Blue analogues (PBAs) which have attracted tremendous attentions in various scientific fields. ${ }^{28,29}$ The method may be also beneficial for the reuse of biomass.

In conclusion, we have prepared Prussian Blue by pyrolysis of carbon, nitrogen and iron precursors in the presence of alkali metal salt and proposed a possible mechanism to explain the formation of Prussian Blue. We believe this work could supply a new insight into the chemistry of Prussian Blue and can lead to some interesting materials for various applications.

\section{Supporting Information}

\section{Experiment section:}

Chemicals and materials: Sucrose and $\mathrm{FeSO}_{4} \cdot 7 \mathrm{H}_{2} \mathrm{O}$ were purchased from Sinopharm Chemical Reagent Co., Ltd.; urea and $\mathrm{K}_{2} \mathrm{SO}_{4}$ were purchased from Shantou Xilong Chemical Co. Ltd,;

$\mathrm{Fe}_{2}\left(\mathrm{SO}_{4}\right)_{3} \cdot \mathrm{xH}_{2} \mathrm{O}$ ( $\mathrm{Fe}$ content is $21-23 \mathrm{wt} \%$ ) was purchased from Beijing Zhonglian Chemical Factory; Glycine was purchased from Tianjin Kermel Chemical Reagents Development Center. All the chemical reagents were used as received without further purification.

Synthesis of Prussian Blue by urea, sucrose, $\mathrm{K}_{2} \mathrm{SO}_{4}$ and $\mathbf{F e}_{2}\left(\mathbf{S O}_{4}\right)_{3}$ : $3.0 \mathrm{~g}$ of sucrose, $3.0 \mathrm{~g}$ of urea, $2.0 \mathrm{~g}$ of $\mathrm{K}_{2} \mathrm{SO}_{4}$ was dissolved in $30 \mathrm{~mL}$ of deionized water and the solution was then mixed with $20 \mathrm{~mL}$ of $0.1 \mathrm{~mol} / \mathrm{L} \mathrm{Fe}_{2}\left(\mathrm{SO}_{4}\right)_{3}$ solution to form a uniform solution by magnetic stirring. In order to avoid the hy drolysis of $\mathrm{Fe}^{3+}, 0.5 \mathrm{~mL}$ of concentrated sulfuric acid (98\%) was added into the solution. The solution was heated in an oven at $40^{\circ} \mathrm{C}$ to evaporate most of water and then at $100^{\circ} \mathrm{C}$ to evaporate the residual water and get a dark material. The dark material was then put into a tube furnace and pyrolysed at $800^{\circ} \mathrm{C}$ for $2 \mathrm{~h}$ under Argon atmosphere, with a heating rate of $2^{\circ} \mathrm{C} / \mathrm{min}$. After cooling, the resulted product was washed by $1.0 \mathrm{~mol} / \mathrm{L}$ chloric acid at $80^{\circ} \mathrm{C}$ for $8 \mathrm{~h}$ and then washed by deionized water and absolute ethanol several times. The resulted product was dried in an oven at $50^{\circ} \mathrm{C}$.

Synthesis of Prussian Blue by glycine, $\mathrm{K}_{2} \mathrm{SO}_{4}, \mathrm{FeSO}_{4}$ and $\mathbf{F e}_{2}\left(\mathbf{S O}_{4}\right)_{3}$ : $3.75 \mathrm{~g}$ of gly cine, $1.45 \mathrm{~g}$ of $\mathrm{K}_{2} \mathrm{SO}_{4}, 0.79 \mathrm{~g}$ of $\mathrm{FeSO}_{4}{ }^{\bullet}$ $7 \mathrm{H}_{2} \mathrm{O}$ was dissolved in $30 \mathrm{~mL}$ of deionized and then mixed with $18.75 \mathrm{~mL}$ of $0.1 \mathrm{~mol} / \mathrm{L} \mathrm{Fe}_{2}\left(\mathrm{SO}_{4}\right)_{3}$. The solution was freezed in a refrigerator $\left(-18^{\circ} \mathrm{C}\right)$ for more than $24 \mathrm{~h}$ and then freeze dried. The following procedure was identical with the case of urea, sucrose, $\mathrm{K}_{2} \mathrm{SO}_{4}$ and $\mathrm{Fe}_{2}\left(\mathrm{SO}_{4}\right)_{3}$.

XRD measurement: The X-ray radiation diffraction (XRD) spectra were recorded on X'Pert Pro diffractormeter with a $\mathrm{Cu} \mathrm{K} \alpha$ radiation $(\lambda=0.15418 \mathrm{~nm})$.

\section{AUTHOR INFORMATION}

\section{Corresponding Author}

*zhangjuny an@licp.cas.cn

Notes

The authors declare no competing financial interests.

\section{ACKNOWLEDGMENT}

This work was supported by the National High Technology R\&D Program (863) of China (Grant No. 863 2015AA034602).

\section{REFERENCES}

(1) Lefevre, M.; Proietti, E.; Jaouen, F.; Dodelet, J. P. Iron-based catalysts with improved oxygen reduction activity in polymer electrolyte fuel cells. Science 2009, 324, 71-74.

(2) Wu, G.; More, K. L.; Johnston, C. M.; Zelenay, P. High-Performance Electrocatalysts for Oxygen Reduction Derived from Polyaniline, Iron, and Cobalt. Science 2011, 332, 443-447.

(3) Jagadeesh, R. V.; Surkus, A. E.; Junge, H.; Pohl, M. M.; Radnik, J.; Rabeah, J.; Huan, H. M.; Schunemann, V.; Bruckner, A.; Beller, M. Nanoscale $\mathrm{Fe}_{2} \mathrm{O}_{3}$-Based Catalysts for Selective Hydrogenation of Nitroarenes to Anilines. Science 2013, 342, 1073-1076.

(4) Pan, F.; Jin, J.; Fu, X.; Liu, Q.; Zhang, J. Advanced Oxygen Reduction Electrocatalyst Based on Nitrogen-Doped Graphene Derived from Edible Sugar and Urea. ACS Appl. Mater. Inter. 2013, 5, 11108-11114.

(5) Liu, Q.; Duan, Y.; Zhao, Q.; Pan, F.; Zhang, B.; Zhang, J. Direct Synthesis of Nitrogen-Doped Carbon Nanosheets with High Surface Area and Excellent Oxygen Reduction Performance. Langmuir 2014, 30, 82388245 .

(6) Vikkisk, M.; Kruusenberg, I.; Joost, U.; Shulga, E.; Kink, I.; Tammeveski, K. Electrocatalytic oxygen reduction on nitrogen-doped graphene in alkaline media. Appl. Catal. B-Environ. 2014, 147, 369-376.

(7) Sheng, Z. H.; Shao, L.; Chen, J. J.; Bao, W. J.; Wang, F. B.; Xia, X. H. Catalyst-Free Synthesis of Nitrogen-Doped Graphene via Thermal Annealing Graphite Oxide with Melamine and Its Excellent Electrocatalysis. ACS Nano 2011, 5, 4350-4358.

(8) Wu, Z. S.; Yang, S.; Sun, Y.; Parvez, K.; Feng, X.; Mullen, K. 3D nitrogen-doped graphene aerogel-supported $\mathrm{Fe} 3 \mathrm{O} 4$ nanoparticles as efficient electrocatalysts for the oxygen reduction reaction. J. Am. Chem. Soc. 2012, 134, 9082-9085.

(9) Wen, Z. H.; Ci, S. Q.; Zhang, F.; Feng, X. L.; Cui, S. M.; Mao, S.; Luo, S. L.; He, Z.; Chen, J. H. Nitrogen-Enriched Core-Shell Structured $\mathrm{Fe} / \mathrm{Fe}_{3} \mathrm{C}-\mathrm{C}$ Nanorods as Advanced Electrocatalysts for Oxygen Reduction Reaction. Adv. Mater. 2012, 24, 1399-1404.

(10) Yang, W. X.; Liu, X. J.; Yue, X. Y.; Jia, J. B.; Guo, S. J. Bamboo-like Carbon Nanotube/Fe3C Nanoparticle Hybrids and Their Highly Efficient Cataly sis for Oxygen Reduction. J. Am. Chem. Soc. 2015, 137, 1436-1439. (11) Lefevre, M.; Dodelet, J. P.; Bertrand, P. Molecular Oxygen Reduction in PEM Fuel Cells: Evidence for the Simultaneous Presence of Two Active Sites in Fe-Based Catalysts. J. Phys. Chem. B 2002, 106, 87058713.

(12) Zitolo, A.; Goellner, V.; Armel, V.; Sougrati, M. T.; Mineva, T.; 
Stievano, L.; Fonda, E; Jaouen, F. Identification of catalytic sites for oxygen reduction in iron- and nitrogen-doped graphene materials. Nat. Mater. 2015, 14,937-942.

(13) Jin, J. T.; Pan, F. P.; Jiang, L. H.; Fu, X. G.; Liang, A. M.; Wei, Z. Y.; Zhang, J. Y.; Sun, G. Q. Catalyst-Free Synthesis of Crumpled Boron and Nitrogen Co-Doped Graphite Layers with Tunable Bond Structure for Oxygen Reduction Reaction. ACS Nano 2014, 8, 3313-3321.

(14) Byon, H. R.; Suntivich, J.; Shao-Horn, Y. Graphene-Based NonNoble-Metal Catalysts for Oxygen Reduction Reaction in Acid. Chem. Mater. 2011, 23, 3421-3428.

(15) Wang, X.; Zou, L.; Fu, H.; Xiong, Y.; Tao, Z.; Zheng, J.; Li, X. Noble Metal-Free Oxygen Reduction Reaction Catalysts Derived from Prussian Blue Nanocrystals Dispersed in Poly aniline. ACS Appl. Mater. Inter. 2016, 8, 8436-8444.

(16) Barman, B. K.; Nanda, K. K. Prussian blue as a single precursor for synthesis of $\mathrm{Fe} / \mathrm{Fe}_{3} \mathrm{C}$ encapsulated $\mathrm{N}$-doped graphitic nanostruct ures as bifunctional catalysts. Green Chem. 2016, 18,427-432.

(17) Coleby, L. J. M. A History of Prussian Blue. Ann. Sci. 1939, 4, $206-$ 211.

(18) Kraft, A. On the Discovery and History of Prussian Blue. Bull. His.t Chem. 2008, 33, 61-67.

(19) Brown, J. Observations and Experiments upon the Foregoing Preparation. By Mr. John Brown, Chymist, FRS. Philos. Trans. 1724, 33, $17-24$.

(20) Powell, H. The Beginnings of Co-ordination Chemistry. Proc. Chem. Soc. 1959, 73-75.

(21) Vähä-Savo, N.; DeMartini, N.; Engblom, M.; Brink, A.; Hupa, M. The Fate of Char Nitrogen in Black Liquor Combustion-Cyanate Formation and Decomposition. Ind. Eng. Chem. Res. 2015, 54, 2831-2842. (22) Dayton, D. C.; Milne, T. A. Laboratory measurements of alkali metal cont aining vapors released during biomass combustion. In Applications of Advanced Technology to Ash-Related Problems in Boilers; Baxter, L., Desollar, R., Eds.; Plenum Press: New York, 1996,p 161-185.

(23) Chem Player. (September 29, 2015). Potassium Cyanate and Reduction to Cyanide? [Video File]. Retrieved from https://www.youtube.com/watch?v=Z6s85zQHtxQ.

(24) Itaya, K; Shoji, N.; Uchida, I. Catalysis of the Reduction of Molecular-Oxygen to Water at Prussian Blue Modified Electrodes. J. Am. Chem. Soc. 1984, 106, 3423-3429.

(25) Peng, Y. Y.; Li, B.; Wang, Y. H.; He, X. Y.; Huang, J. X.; Zhao, J. B. Prussian Blue: A Potential Material to Improve the Electrochemical Performance of Lithium-Sulfur Batteries. ACS Appl. Mater. Inter. 2017, 9, 4397-4403.

(26) Lu, Y.; Wang, L.; Cheng, J.; Goodenough, J. B. Prussian Blue: a New Framework of Electrode Materials for Sodium Batteries. Chem. Commun. 2012, 48, 6544-6546.

(27) Zhang, Y.; Sun, X.; Zhu, L.; Shen, H.; Jia, N. Electrochemical Sensing Based on Graphene Oxide/Prussian Blue Hybrid Film Modified Electrode. Electrochim. Acta 2011, 56, 1239-1245.

(28) Escax, V.; Bleuzen, A.; Cartier dit Moulin, C.; Villain, F.; Goujon, A.; Varret, F; Verdaguer, M. Photoinduced Ferrimagnetic Systems in Prussian Blue Analogues $\mathrm{C}_{\mathrm{x}}^{\mathrm{I}} \mathrm{Co}_{4}\left[\mathrm{Fe}(\mathrm{CN})_{6}\right]_{y}\left(\mathrm{C}^{\mathrm{I}}=\right.$ Alkali Cation $)$. 3. Control of the Photo-and Thermally Induced Electron Transfer by the $\left[\mathrm{Fe}(\mathrm{CN})_{6}\right]$ Vacancies in Cesium Derivatives. J. Am. Chem. Soc. 2001, 123, 1253612543.

(29) Kaye, S. S.; Long, J. R. Hydrogen Storage in the Dehydrated Prussian Blue Analogues $\mathrm{M}_{3}\left[\mathrm{Co}(\mathrm{CN})_{6}\right]_{2}(\mathrm{M}=\mathrm{Mn}, \mathrm{Fe}, \mathrm{Co}, \mathrm{Ni}, \mathrm{Cu}, \mathrm{Zn})$. J. Am. Chem. Soc. 2005, 127, 6506-6507. 